\title{
Different cardiac loading conditions and haemodynamic monitoring in animal models
}

\author{
Kobr $\mathbf{J}^{1}$, Treska $\mathrm{V}^{2}$, Molacek $\mathbf{J}^{2}$, Kuntscher $\mathrm{V}^{2}$, Liska $\mathrm{V}^{2}$, Koppl $\mathbf{J}^{3}$ \\ Department of Paediatrics - PICU, Charles University in Prague, Faculty of Medicine in Pilsen, Czech Republic. \\ kobr@fnplzen.cz
}

\begin{abstract}
Objective: To develop models of various cardiac loading conditions in an experimental study. Materials and methods: A total of 78 piglets, average weight $24 \mathrm{~kg}$ were divided into 4 groups under different cardiac loading conditions: Group A were spontaneously breathing pigs without haemodynamic changes, Group $B$ were ventilated animals with increased left ventricular afterload, Group $C$ ventilated with increased right ventricular preload and Group D ventilated with increased afterload of both heart ventricles. Haemodynamic parameters were invasively measured at 60 and 120 minutes.

Results: Groups B, C and D demonstrated higher preload of both ventricles, compared with Group A. Group C demonstrated higher preload and afterload of both ventricles in comparison with Groups B and D.

Conclusion: Haemodynamic measured data confirmed the expected changes in cardiac loading and corresponded to human clinical situations. These models may be used for future experimental haemodynamic studies (Tab. 1, Fig. 3, Ref. 8). Full Text in PDF www.elis.sk.

Key words: pulmonary artery thermodilution, cardiac output, piglets.
\end{abstract}

Accurate assessment of cardiac output and myocardial function has been considered vital in the successful treatment of critically ill patients. In paediatric clinical practice, it is necessary to decide on precisely which methods should be employed to technically monitor the haemodynamics of these patients during mechanical ventilation.

The use of transpulmonary intermittent thermo-dilution for cardiac output measurements via an in-dwelling pulmonary arterial catheter is considered one of the most reliable haemodynamic monitoring methods in paediatric patients (1). Invasive right heart catheterization in newborns and infants, however, is not devoid of potential risks (2).

Experimental animal models may be considered in determining the reference values, as well as the sensitivity and specificity of other less invasive methods in measuring cardiac output.

${ }^{1}$ Department of Paediatrics - PICU, Charles University in Prague, Faculty of Medicine in Pilsen, ${ }^{2}$ Department of Surgery, Charles University in Prague, Faculty of Medicine in Pilsen, Czech Republic, ${ }^{3}$ Department of Paediatrics Anaesthesiology and Intensive Care, Comenius University and Children University Hospital Bratislava, Slovak Republic.

Address for correspondence: J. Kobr, MD, PhD, Charles University in Prague, Faculty of Medicine in Pilsen, Alej Svobody 80, CZ-304 60 Pilsen, Czech Republic.

Acknowledgements: The study was supported by Research Project of Charles University in Prague, Faculty of Medicine in Pilsen No. MSM 0021160819-6096, grants the Ministry of Health of the Czech Republic IGA no. NA/7653-3, NR/7909-3, and grant of the Charles University GA no. $82 / 2000 /$ C/LFP

We thank Mr. RNDr. František Šefrna, PhD, as a consultant-statististician of our work and for active cooperation. Special acknowledgement goes to fellow Konrad K. Siala, MD, PhD, for his linguistic correction.

\section{Materials and methods}

The study was conducted with the approval of a multidisciplinary institutional ethics committee in an EU accredited experimental centre of the Faculty of Medicine of Charles University in Pilsen, Czech Republic. Respecting the principles of Helsinki Declaration this study was part of ongoing experimental studies.

Seventy-eight clinically healthy piglets (aged 6 weeks, mean weight $24 \mathrm{~kg}$ with a range of $18-27 \mathrm{~kg}$, male to female ratio $1: 3$ ) were anaesthetized, endotracheally intubated, catheterized and divided into 4 groups: Control Group A ( $n=34)$ - spontaneously breathing animals without surgical intervention or changes in haemodynamics. After completing the measurements in this control group, the generally anesthetized animals were divided into two groups according to further surgical interventions: Group B ( $\mathrm{n}=17)$ animals were muscle relaxed and mechanically ventilated and with an increased left ventricular afterload induced by cross clamping of the abdominal aorta above the origin of the renal arteries (3); Group $\mathrm{C}(\mathrm{n}=17)$ were muscle relaxed and mechanically ventilated animals with increased right ventricular preload induced by $50 \%$ occlusion of the portal bed via right portal vein embolisation. This significant reduction of blood flow into the portal bed led to increased flow into the inferior vena cava and thus increased return of venous blood into the right atrium (4); Group D $(n=44)$ animals underwent abdominal aortic tight banding 3 weeks before study commencement. These animals were muscle relaxed and mechanically ventilated with increased afterload of the right ventricle-induced by a high tidal volume strategy of mechanical ventilation (5).

The internal jugular vein was cannulated for central venous access using the Seldinger percutaneous technique and a Swan-Ganz 
$131-134$

thermodilution pulmonary catheter was introduced. The femoral artery was used for direct arterial blood pressure monitoring via the arterial catheter.

\section{General anaesthesia and ventilator support}

Premedication was given by intramuscular administration of atropine $0.07 \mathrm{mg} / \mathrm{kg}$ and azaperone $5.0 \mathrm{mg} / \mathrm{kg}$. General anaesthesia was induced by intravenous administration of thiopental $10 \mathrm{mg} /$ $\mathrm{kg}$ and all animals were orotracheally intubated. Combined general anaesthesia was maintained by intravenous fentanyl 0.5-1.0 microg $/ \mathrm{kg}$ with azaperone $3.0-4.0 \mathrm{mg} / \mathrm{kg}$ and peripheral muscle paralysis using pancuronium $0.1-0.2 \mathrm{mg} / \mathrm{kg}$ (6).

Animals in Group A were breathing spontaneously with continuous positive airway pressure support at $2 \mathrm{cmH}_{2} \mathrm{O}$ and $\mathrm{FiO}_{2}$ 0.21 . Animals in Groups B, C, and D were mechanically ventilated using a servo-ventilator (Servo Elema 900C, Siemens; Germany) in pressure controlled mode with the following settings: $\mathrm{P}_{\text {insp }} 15$ $\mathrm{cmH}_{2} 0$, rate 24 breath/min, PEEP $6 \mathrm{cmH}_{2} \mathrm{O}$, I:E 0.7, $\mathrm{FiO}_{2} 0.21$ in Groups B, and C. In Group D settings were deliberately not physiological: $\mathrm{P}_{\text {insp }} 30 \mathrm{cmH}_{2} 0$, rate 30 breath/min., PEEP $0 \mathrm{cmH}_{2} \mathrm{O}, \mathrm{I}: \mathrm{E}$ $1.0, \mathrm{FiO}_{2} 0.21$.

\section{Study protocol}

Experimental work in all piglets utilized tracheal intubation and establishing invasive entry under general anaesthesia. Following a sixty minute recovery period the first transpulmonary thermodilution measurement reading was taken (time-1) and after a further sixty minutes, all measurements were repeated (time-2).

Measurement of cardiac output and haemodynamic data acquisition

Cardiac output was measured by intermittent pulmonary artery thermodilution. Under ultrasound guidance a Swan-Ganz thermodilution catheter was positioned in the pulmonary artery. Pressure curve during the introduction of pulmonary artery catheters is documented in the scheme in Figure 1.

The average temperature of $38.5^{\circ} \mathrm{C}$ measured in the pulmonary artery allowed for adequate thermal difference with the test solu-

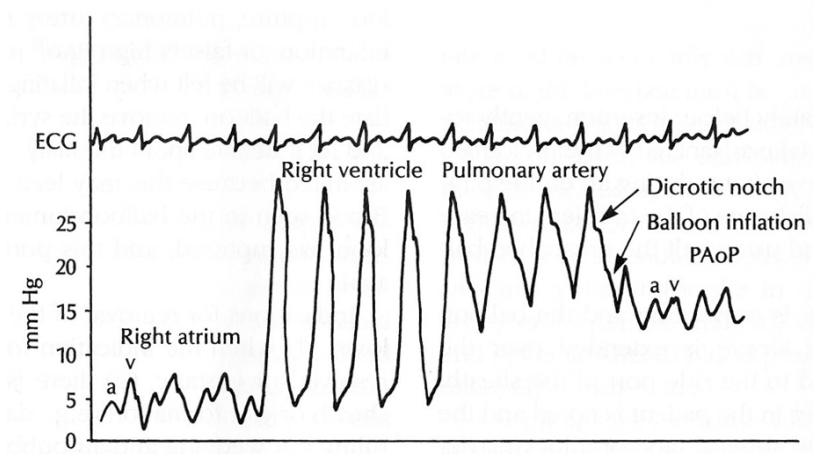

Fig. 1. Pressure curve of pulmonary artery catheters. Legend: The diagram shows the usual changes in the pressure curve during the introduction of the PAC and the correct position for intermittent thermodilution measurement of haemodynamics. Wave 'a' expresses the atrial contraction and wave ' $v$ ' contraction of the heart ventricles.
SVR

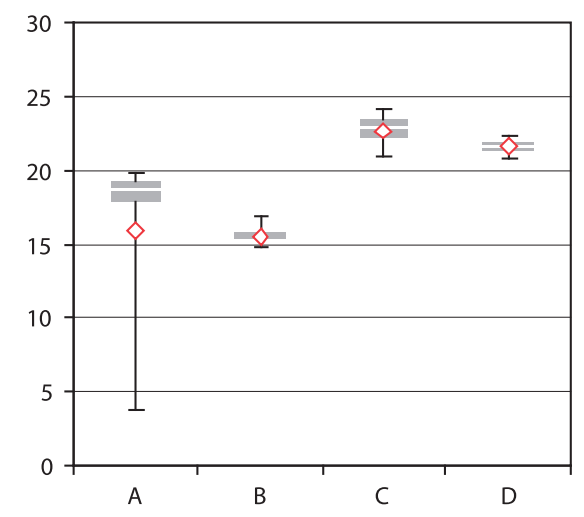

Fig. 2. The values of systemic vascular resistance during the study in the groups A, B, C and D. Legend: SVR - systemic vascular resistance; $n=122$ data, $A$ - spontaneously breathing animals with normal haemodynamic in control group A; B - ventilated animals with increased left ventricle afterload in the group $\mathrm{B} ; \mathrm{C}$ - ventilated animals with increased right ventricle preload in the group $C$; D - ventilated animals with increased afterload of the both ventricles in the group $D$.

PVR

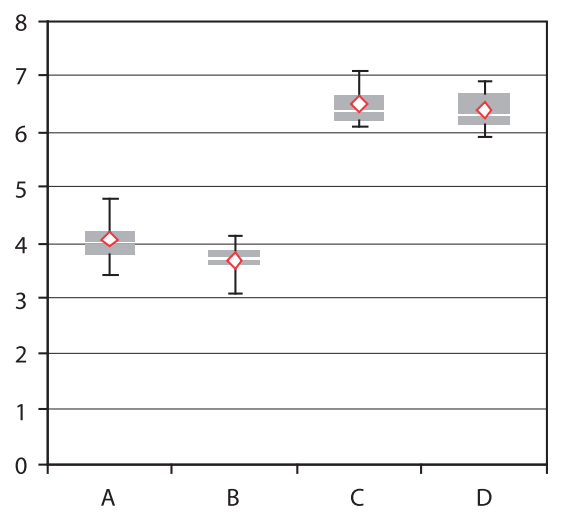

Fig. 3. Values of total pulmonary vascular resistance during the study in groups A, B, C and D. Legend: PVR - pulmonary vascular resistance; $n=122$ data, $A$ - spontaneously breathing animals with normal haemodynamic in control group A; B - ventilated animals with increased left ventricle afterload in the group B; C - ventilated animals with increased right ventricle preload in the group $C$; D - ventilated animals with increased afterload of the both ventricles in the group D.

tion $\left(0.9 \mathrm{M}\right.$ sodium chloride at $\left.21^{\circ} \mathrm{C}\right)$. The standard technique was used to assess cardiac output by rapidly injecting the test solution into the proximal port of the pulmonary artery catheter with subsequent temperature monitoring at the catheter tip. The following haemodynamic data were acquired, calculated and recorded: heart rate, mean central venous pressure, right heart ventricle pressure, pulmonary arterial pressure, pulmonary arterial occlusive (wedge) pressure, mean arterial pressure (MAP), stroke volume, cardiac output and cardiac index, systemic vascular resistance (MAP$\mathrm{CVP} / \mathrm{CO}$ ), pulmonary arteriolar-vascular resistance (PAP-PAoP/ $\mathrm{CO})$. The body surface area of each animal was calculated using Meehe's formula: $0.087 \mathrm{x}$ weight $/ 0.66\left(\mathrm{~m}^{2}\right)(1)$. Each parameter 
Tab. 1. Values in each group and the differences observed in the values of observed indices between Groups B, C, D and Group A (n=122).

\begin{tabular}{|c|c|c|c|c|c|c|c|}
\hline Variables & $\begin{array}{c}\text { Group A n }=68 \\
\text { Mean } \pm \text { SD }(95 \% \text { CI })\end{array}$ & $\begin{array}{c}\text { Group B } n=34 \\
\text { Mean } \pm \text { SD }(95 \% \mathrm{CI})\end{array}$ & $\begin{array}{c}\text { Values } \\
\mathrm{p}<\end{array}$ & $\begin{array}{c}\text { Group C } \mathrm{n}=34 \\
\text { Mean } \pm \text { SD }(95 \% \mathrm{CI})\end{array}$ & $\begin{array}{c}\text { Values } \\
\mathrm{p}<\end{array}$ & $\begin{array}{c}\text { Group D } n=88 \\
\text { Mean } \pm \text { SD }(95 \% \mathrm{Cl})\end{array}$ & $\begin{array}{c}\text { Values } \\
\mathrm{p}<\end{array}$ \\
\hline HR & $\begin{array}{c}158.00 \pm 19.40 \\
(148.07-165.13)\end{array}$ & $\begin{array}{c}161.02 \pm 19.42 \\
(150.07-163.45)\end{array}$ & NS & $\begin{array}{c}160.05 \pm 19.12 \\
(149.22-173.30)\end{array}$ & NS & $\begin{array}{c}161.11 \pm 19.60 \\
(145.07-179.10)\end{array}$ & NS \\
\hline CVP & $\begin{array}{l}1.81 \pm 2.17 \\
(1.00-2.00)\end{array}$ & $\begin{array}{l}2.80 \pm 2.61 \\
(3.31-4.91)\end{array}$ & 0.05 & $\begin{array}{c}5.60 \pm 2.42 \\
(4.81-6.50)\end{array}$ & 0.01 & $\begin{array}{c}3.60 \pm 2.33 \\
(2.90-4.31)\end{array}$ & 0.01 \\
\hline RVP & $\begin{array}{c}9.04 \pm 1.87 \\
(8.03-9.01)\end{array}$ & $\begin{array}{c}9.45 \pm 1.74 \\
(9.15-14.31)\end{array}$ & 0.05 & $\begin{array}{c}14.43 \pm 3.04 \\
(13.43-15.41)\end{array}$ & 0.01 & $\begin{array}{c}14.12 \pm 2.30 \\
(13.41-14.81)\end{array}$ & 0.01 \\
\hline PAP & $\begin{array}{c}16.02 \pm 3.13 \\
(14.02-17.82)\end{array}$ & $\begin{array}{c}16.50 \pm 2.53 \\
(14.70-17.80)\end{array}$ & NS & $\begin{array}{c}17.21 \pm 5.30 \\
(15.31-19.07)\end{array}$ & 0.05 & $\begin{array}{c}18.04 \pm 4.73 \\
(14.90-20.20)\end{array}$ & NS \\
\hline PAoP & $\begin{array}{c}6.91 \pm 5.87 \\
(7.04-10.01)\end{array}$ & $\begin{array}{c}10.64 \pm 2.33 \\
(9.82-11.31)\end{array}$ & 0.01 & $\begin{array}{c}13.53 \pm 2.44 \\
(12.72-14.33)\end{array}$ & 0.01 & $\begin{array}{c}12.60 \pm 2.72 \\
(11.81-13.40)\end{array}$ & 0.01 \\
\hline MAP & $\begin{array}{c}75.52 \pm 4.30 \\
(73.12-78.04)\end{array}$ & $\begin{array}{c}75.80 \pm 3.74 \\
(72.81-78.41)\end{array}$ & NS & $\begin{array}{c}75.22 \pm 3.30 \\
(72.61-77.30)\end{array}$ & NS & $\begin{array}{c}74.74 \pm 3.50 \\
(71.80-78.12)\end{array}$ & NS \\
\hline SV & $\begin{array}{c}18.03 \pm 2.50 \\
(16.04-19.02)\end{array}$ & $\begin{array}{c}17.93 \pm 2.84 \\
(15.61-19.51)\end{array}$ & NS & $\begin{array}{c}15.21 \pm 2.62 \\
(14.04-17.31)\end{array}$ & 0.01 & $\begin{array}{c}16.04 \pm 2.60 \\
(15.70-17.91)\end{array}$ & 0.01 \\
\hline CI & $\begin{array}{c}2.91 \pm 0.98 \\
(1.95-3.02)\end{array}$ & $\begin{array}{c}2.66 \pm 0.83 \\
(2.02-3.01)\end{array}$ & NS & $\begin{array}{c}1.94 \pm 1.01 \\
(1.46-2.72)\end{array}$ & 0.01 & $\begin{array}{c}2.04 \pm 1.10 \\
(1.64-2.77)\end{array}$ & 0.01 \\
\hline $\mathrm{CO}$ & $\begin{array}{l}1.34 \pm 0.30 \\
(1.11-1.53)\end{array}$ & $\begin{array}{c}1.25 \pm 0.28 \\
(1.03-1.44)\end{array}$ & NS & $\begin{array}{c}0.64 \pm 0.37 \\
(0.52-0.77)\end{array}$ & 0.01 & $\begin{array}{c}0.71 \pm 0.34 \\
(0.60-0.81)\end{array}$ & 0.01 \\
\hline MAP-CVP & $\begin{array}{c}73.71 \pm 2.13 \\
(74.31-76.29)\end{array}$ & $\begin{array}{c}74.22 \pm 1.78 \\
(73.90-75.73)\end{array}$ & NS & $\begin{array}{c}69.13 \pm 3.8 \\
(67.81-70.54)\end{array}$ & 0.01 & $\begin{array}{c}72.03 \pm 3.34 \\
(71.01-73.05)\end{array}$ & 0.05 \\
\hline SVR & $\begin{array}{l}1580.03 \pm 680.31 \\
(1830.0-1920.2)\end{array}$ & $\begin{array}{l}1595.07 \pm 480.01 \\
(1490.4-1975.0)\end{array}$ & NS & $\begin{array}{l}2435.12 \pm 130.20 \\
(2210.2-2570.1)\end{array}$ & 0.01 & $\begin{array}{l}2370.11 \pm 392.08 \\
(2260.3-2550.1)\end{array}$ & 0.01 \\
\hline PVR & $\begin{array}{c}404.17 \pm 52.23 \\
(378.34-420.22) \\
\end{array}$ & $\begin{array}{c}409.02 \pm 58.32 \\
(382.11-437.40)\end{array}$ & NS & $\begin{array}{c}440.01 \pm 82.24 \\
(411.02-469.17) \\
\end{array}$ & 0.01 & $\begin{array}{c}429.01 \pm 77.31 \\
(405.10-452.44) \\
\end{array}$ & 0.01 \\
\hline
\end{tabular}

Legend: HR, heart rate (beat/min); CVP, mean central venous pressure ( $\mathrm{mmHg}$ ); RVP, mean right ventricle pressure (mmHg); PAP, mean pulmonary artery pressure (mmHg); PAoP, mean pulmonary artery occlusive pressure (mmHg); MAP, mean artery pressure ( $\mathrm{mmHg}$ ); $\mathrm{SV}$, stroke volume (ml); CO, cardiac output (1/min); CI, cardiac index (1/ $\mathrm{min} / \mathrm{m} 2$ ); MAP-CVP, difference of mean systemic pressures (mmHg); SVR, systemic vascular resistance (dyn.sec/cm5); PVR, pulmonary vascular resistance (dyn.sec/cm5) NS, not significant; $p<$, values $p$

was expressed as a mean value using 5 consecutive measurements at 30 second intervals.

\section{Statistical analysis}

Parametric data were expressed as mean, significant difference (SD) and $95 \%$ confidence interval $(95 \% \mathrm{CI})$. Pearson's analysis and polynominal regression was used to compare the data obtained. For qualitative analysis of accuracy of the reproducibility agreement was used (7). p values $<0.05$ were considered statistically significant. All data were analysed using statistical software (Analyze-it211 Software Ltd.; USA).

\section{Results}

A total of 122 data were acquired in the study. Differences between the data from all monitored haemodynamic indices obtained in time- 1 and time-2, and differences in quality measurements between different groups of animals were not statistically significant.

In all ventilated animals in Groups B, C and D the values of right ventricle preload $(\mathrm{CVP} ; \mathrm{p}<0.05)$ and left ventricle preload (PAoP; $\mathrm{p}<0.01$ ) were higher compared with spontaneously breathing animals in Group A.

Data values in each group and the differences in observed indices values between Groups B, C, D and control Group A are listed in Table 1.
In Group $C$ the values of right ventricle preload (CVP; $p<0.01$ ), right ventricle afterload (PVR; $\mathrm{p}<0.01$ ), left ventricle preload $(\mathrm{PAoP} ; \mathrm{p}<0.01)$ and left ventricle afterload (SVR; $<<0.01)$ were higher in comparison with Group B and Group D.

The values of systemic and pulmonary vascular resistance correlated with expressed afterload of the left and right ventricle. Their values obtained during the study are graphically expressed for groups A, B, C and D in Figs 2 and 3.

\section{Discussion}

Changes in systemic haemodynamic and interactions during mechanical ventilation play an important role in paediatric intensive care medicine. Cardiopulmonary interaction plays an essential role in critically ill patients. Animal models are important research tools for verification of monitoring techniques and treatment strategies. To create a haemodynamic model, we chose the domestic pig, which has a very similar morphology and physiology of the cardiopulmonary system as humans (8).

The piglets with cross clamping of the abdominal aorta above the origin of renal arteries in Group B (3) comprised a haemodynamic model of increased afterload and left ventricular diastolic dysfunction. In this group changes in cardiac output and haemodynamic parameters were the smallest. This experimental model theoretically corresponds to patients with systemic arterial 
$131-134$

hypertension or acute obliteration at the level of the large arteries. Our theoretical model did not fulfill out expectations. It has not shown a significant elevation in systemic vascular resistance values or a decrease in cardiac output. This can be explained by vasodilation autoregulatory mechanisms of the experimental organism. Furthermore, perioperative occlusion was short, less than 60 minutes. In summary, the data for 60 and 120 min occlusion are not applicable with regard to elevation of systemic vascular resistance.

The animals with partial occlusion of the portal bed via right portal vein embolization. In the normal course of events the high volume of venous blood from the digestive tract of unpaired organs arises through the portal circulation to the liver on the basis of a pressure gradient. Partial occlusion of the portal venous bed causes transient changes in this pressure gradient and regional haemodynamic in Group C (4). Immediate adaptation after surgery leads to a several hour reduction in liver flow, and conversely increases flow through the natural porto-systemic connections into the lower vena cava. Temporary increase in flow in the lower vena cava was used to create an experimental model of increased preload and right atrial diastolic filling. Our study detected in this model the most significant change in haemodynamic during mechanical lung ventilation with rapid elevation of preload and afterload values of both heart ventricles.

The model corresponds to the paediatric patient with significant left-right shunt such as the uncorrected congenital heart defect.

Piglets underwent abdominal aortic tight banding three weeks before study start in Group D (5), and were ventilated by high tidal volume strategy. The combination of flow-limiting abdominal aorta and increasing pressure in the chest created a haemodynamic model of the increased afterload and the diastolic dysfunction of both heart ventricles. In this group there was a rapid change in cardiac output and haemodynamic parameters, but less significant $(\mathrm{p}<0.05)$ compared with group C.

Experimental model corresponds to the patients in the hyperdynamic phase of shock.

At our Paediatric Intensive Care Unit, $75 \%$ of physicians are trained in echocardiography, whilst only $5 \%$ are experienced in thermo-dilution techniques. It was a logical step for us to scientifically confirm that the global preferred trend of minimally invasive techniques in determining cardiac performance, is comparable to the so-called gold standard in monitoring haemodynamics via a pulmonary catheter.

Additional limitations of this study may include the fact that the study duration was more than 6 years. As the fundamental aim of the study was to achieve the greatest amount of data from a very large number of haemodynamically compromised animals, it was a logistical problem to achieve this in a shorter period of time. As the investigator, apparatus and experimental conditions throughout the entire length of the study remained constant, we feel that the end result is minimally influenced by bias.

\section{References}

1. Takano JS. Chapter 133: Advanced haemodynamic monitoring: Pulmonary artery and left atrial cathetrization. In: Essentials of Paediatric Intensive Care. DL Levin, FC Morris, 2nd Edd. Churchill Livingstone Inc., 1997: 1234-1248.

2. Carmosino M, Friesen RH, Doran A, Ivy DD. Perioperative complications in children with pulmonary hypertension undergoing noncardiac surgery or cardiac catheterization. Anesth Analg 2007; 104 (3): 521-527.

3. Treska V, Kuntscher V, Molacek J, Kobr J, Racek J, Trefil L. Can ischemia- reperfusion syndrome in transplanted kidneys procedure from non-heart-beating donors be influenced by adding selenium into the reperfusion solution? An experimental study. Transplant Proc 2003; 35 (8): 3125-3127.

4. Liska V, Slowik P, Eggenhofer E, Treska V, Renner P, Popp FC, Mirka H, Kobr J, Sykora R, Schlitt HJ, Holubec L, Chlumska A, Skalicky T, Matejovic M, Dahlke MH. Intraportal injection of porcine multipotent mesenchymal stromal cells augments liver regeneration after portal vein embolization. In Vivo 2009; 23: 229-236.

5. Molacek J, Treska V, Kobr J, Certik B, Skalicky T, Kuntscher V, Krizkova V. Optimalization of the model of abdominal aortic aneurysm. Experiment in an animal model. J Vasc Res 2009; 526: 1-5

6. Jacson PG, Cockroft P: Analgesia, anesthesia, and surgical procedures in the pig. In: Handbook of Pig Medicine. PG Jacson, P Cocroft, Saunders Elsevier, 2007: 30-241

7. Bland JM, Altman DG. Statistical methods for assessing agreement between two methods of clinical measurement. Lancet 1986; 1: 307-310

8. Jacson PG: Chapter no. 4, Diseases of the respiratory system. In: Jackson PG, Cockcroft P. Handbook of Pig Medicine, Saunders Elsevier, 2007: $70-82$. 